\title{
Cardiometabolic Risk Variables in Preadolescent Children: A Factor Analysis
}

\section{Citation}

Stoner, Lee, Mark Weatherall, Paula Skidmore, Nicholas Castro, Sally Lark, James Faulkner, and Michelle A. Williams. 2017. "Cardiometabolic Risk Variables in Preadolescent Children: A Factor Analysis." Journal of the American Heart Association: Cardiovascular and Cerebrovascular Disease 6 (10): e007071. doi:10.1161/JAHA.117.007071. http:// dx.doi.org/10.1161/JAHA.117.007071.

\section{Published Version}

doi:10.1161/JAHA.117.007071

\section{Permanent link}

http://nrs.harvard.edu/urn-3:HUL.InstRepos:34652043

\section{Terms of Use}

This article was downloaded from Harvard University's DASH repository, and is made available under the terms and conditions applicable to Other Posted Material, as set forth at http:// nrs.harvard.edu/urn-3:HUL.InstRepos:dash.current.terms-of-use\#LAA

\section{Share Your Story}

The Harvard community has made this article openly available.

Please share how this access benefits you. Submit a story.

Accessibility 


\section{Cardiometabolic Risk Variables in Preadolescent Children: A Factor Analysis}

Lee Stoner, PhD, MPh; Mark Weatherall, PhD; Paula Skidmore, PhD; Nicholas Castro, MEd; Sally Lark, PhD; James Faulkner, PhD; Michelle A. Williams, ScD

Background-Atherosclerosis begins during preadolescence and is occurring at an accelerated rate. This acceleration has been linked to poor lifestyle behaviors and subsequent cardiometabolic complications. Although the clustering of cardiometabolic risk factors has been recognized for over 2 decades, previous studies in children have predominantly examined the relationships between atherosclerosis and individual cardiometabolic risk factors or have grouped together preadolescent and adolescent children. Further, no known studies have included glycated hemoglobin or central hemodynamic measures such as central systolic blood pressure and augmentation index.

Methods and Results_Principal component analysis was performed on a cross-sectional sample of 392 children (aged 9.5 years, $50 \%$ girls) from 3 representative sample sites across New Zealand. Four factors explained $60 \%$ of the variance in the measured variables. In order of variance explained, the factors were: blood pressure (central systolic blood pressure and peripheral systolic and diastolic blood pressure), adiposity (waist circumference, body mass index, and glycated hemoglobin), lipids (total cholesterol, low-density lipoprotein cholesterol, and high-density lipoprotein cholesterol), and vascular (augmentation index, heart rate, and fasting blood glucose).

Conclusions - In accordance with previous findings in adults and adolescents, one common factor is unlikely to define cardiometabolic health in preadolescent children. Each of the factors, except vascular, which was predominantly explained by augmentation index, are in agreement with previous findings in adolescents. An additional novel finding was that glycated hemoglobin and fasting blood glucose loaded onto different factors, supporting previous work suggesting that fasting blood glucose indicates short-term glycemic control, whereas glycated hemoglobin reflects chronic glycemic control.

Clinical Trial Registration-URL: www.anzctr.org.au/. ID: ACTRN12614000433606. (J Am Heart Assoc. 2017;6:e007071. DOI: 10.1161/JAHA.117.007071.)

Key Words: cardiovascular • glycated hemoglobin • obesity • principal components analysis • pulse wave analysis

$\mathrm{T}^{\mathrm{t}}$ he clinical manifestations of cardiovascular disease typically appear during middle age, but the underlying atherosclerotic process has a long asymptomatic phase of development that often starts during early childhood, and it

From the Department of Exercise and Sport Science, University of North Carolina at Chapel Hill, NC (L.S.); Department of Medicine, University of Otago, Wellington, New Zealand (M.W.); Department of Human Nutrition, University of Otago, Dunedin, New Zealand (P.S.); School of Sport and Exercise, Massey University, Wellington, New Zealand (N.C., S.L.); Department of Sport \& Exercise, University of Winchester, United Kingdom (J.F.); Department of Epidemiology, Harvard T.H. Chan School of Public Health, Boston, MA (M.A.W.). Correspondence to: Lee Stoner, PhD, MPh, Department of Exercise and Sport Science, University of North Carolina, Fetzer Hall, 210 South Road, Wellington, NC 27514. E-mail: dr.I.stoner@gmail.com

Received July 10, 2017; accepted August 9, 2017.

(C) 2017 The Authors. Published on behalf of the American Heart Association, Inc., by Wiley. This is an open access article under the terms of the Creative Commons Attribution-NonCommercial License, which permits use, distribution and reproduction in any medium, provided the original work is properly cited and is not used for commercial purposes. seems likely that this process is occurring at an increasingly younger age. ${ }^{1-3}$ Accelerated progression of atherosclerosis is linked to poor lifestyle behaviors, which, in turn, also contribute to cardiometabolic risk factors, including obesity. $^{3-5}$ The clustering of cardiometabolic risk factors has been recognized for over 2 decades, ${ }^{6}$ but past studies in children mainly explore associations between atherosclerosis and individual cardiometabolic risk factors, rather than overall cardiometabolic risk. ${ }^{1,2}$ Relatively few studies report details of the clustering of components of cardiometabolic components in children. ${ }^{7-14}$ Further, the majority of these studies group together preadolescents and adolescents. ${ }^{7-10}$ In addition, we were unable to identify studies of this kind that have included glycated hemoglobin $\left(\mathrm{HbA}_{1 \mathrm{c}}\right)$, central hemodynamic measures such as central systolic blood pressure (cSBP), or a measurement of arterial wave reflection such as the augmentation index (Alx).

Studies that explore clustering of cardiometabolic risk factors in children or adolescents have included fasting blood 


\section{Clinical Perspective}

\section{What Is New?}

- This study investigated the clustering of 13 cardiometabolic variables in preadolescent children.

- Several novel cardiometabolic variables were included: glycated hemoglobin, central blood pressure, and augmentation index.

- Findings are generally in accordance with those for adolescents and adults.

- However, the inclusion of augmentation index resulted in a novel factor.

- Additionally, glycated hemoglobin and fasting blood glucose loaded onto different factors.

\section{What Are the Clinical Implications?}

- One common factor is unlikely to define cardiometabolic health in preadolescent children.

- Augmentation index is a novel risk factor.

- Glycated hemoglobin and fasting blood glucose provide different information.

- The identified factors may enable the early identification of at-risk populations and help in the design of longitudinal studies.

glucose (FBG), ${ }^{10-12}$ which is a standard component for defining metabolic syndrome in adults and in children aged 10 years and older. ${ }^{15}$ However, FBG indicates short-term glycemic control, ${ }^{16}$ whereas $\mathrm{HbA}_{1 \mathrm{c}}$ reflects chronic glycemic control. ${ }^{17}$ Findings in adults suggest that $\mathrm{HbA}_{1 \mathrm{c}}$ and $\mathrm{FBG}$ have different patterns of association with cardiovascular risk profiles. ${ }^{18}$ For example, $\mathrm{HbA}_{1 \mathrm{c}}$ is more strongly associated with increased risk of cardiovascular events than FBG. ${ }^{19,20}$ We could identify no studies that explored whether $\mathrm{HbA}_{1 \mathrm{c}}$ and FBG are differentially associated with cardiovascular risk profiles in children.

Although past research in this area has included peripheral blood pressure (BP) when examining cardiometabolic risk clustering in children, ${ }^{10-12}$ this may not accurately reflect the effects of peak arterial BP on centrally located organs. ${ }^{21}$ The prognostic value of cSBP has been recognized by expert consensus, ${ }^{22,23}$ and a meta-analysis ${ }^{24}$ reports that cSBP is more strongly associated with the risk of future cardiovascular events than peripheral BP. Furthermore, the degree of central pressure augmentation, Alx, also predicts future cardiovascular events and all-cause mortality in models that also adjust for peripheral or central BP. ${ }^{24,25}$ The advent of oscillometric pulse wave analysis devices permit measures of $\mathrm{CSBP}$ and Alx relatively simply, accurately, ${ }^{26}$ and precisely. ${ }^{27}$

The aims of the study reported here are to explore: (1) underlying factors associated with individual cardiometabolic risk factors in preadolescents using principal components analysis; (2) the unique value of $\mathrm{HbA}_{1 \mathrm{c}}, \mathrm{cSBP}$, and $\mathrm{Alx}$ in these factors; and finally (3) the associations between being overweight or obese in preadolescent children in relation to these underlying factors. Considering that the atherosclerotic process often begins during childhood, and cardiometabolic risk factors tend to cluster, findings from this study may enable the early identification of at-risk populations and may help in the design of longitudinal studies of trajectories of cardiometabolic risk.

\section{Methods}

This nonexperimental observational study was performed in accordance with STROBE (Strengthening the Reporting of Observational Studies in Epidemiology) guidelines. ${ }^{28}$

\section{Participants and Study Design}

Children aged between 8 and 10 years were recruited from schools in 3 major cities in New Zealand: Wellington, Christchurch, and Dunedin. In New Zealand, nearly all schools are publicly funded and currently classified by the predominant socioeconomic status of attending students in a decile classification system. Funding for schools is partly determined by this system so that schools with pupils from deprived areas (decile 1) attract more funding than those from those from wealthy areas (decile 10). In order to recruit children from a variety of socioeconomic backgrounds, schools within the 3 cities were stratified by high (6-10) or low (1-5) decile, and then randomly sampled from within these strata. Within schools, all children in the appropriate age range were eligible for participation, except those prescribed any cardiovascular medications or with an orthopedic injury in the past 3 months. Parental or guardian consent and child assent were obtained before participation, in accordance with the requirements of the New Zealand Health and Disability Ethics Committee (14/CEN/83). The trial was prospectively registered with the Australia and New Zealand Clinical Trial Registry (ACTRN12614000433606).

The data and analyses described in this article were part of a larger cross-sectional study of the associations between measurements of cardiac and metabolic variables and measurements related to physical performance, the PACMAC (PreAdolescent Cardio-Metabolic Associations and Correlates), and details of the larger study have been previously published. ${ }^{29}$ All measurements described in this article were assessed in the child participants' schools between 9 AM and $12 \mathrm{PM}$ and children were asked to have been fasting for at least 3 hours and to have refrained from exercise for 24 hours before assessment. 


\section{Anthropometric and Body Composition}

Body weight was assessed to the nearest $0.05 \mathrm{~kg}$ using an electric scale (A\&D Instruments), with children assessed in light clothing without shoes or other footwear, and height to the nearest $0.1 \mathrm{~cm}$ with a stadiometer, with children in bare feet (Surgical and Medical Products). Waist circumference was measured using nonelastic tape (Seca) during midexpiration at the midpoint between the lower costal margin and the level of the anterior superior iliac crest. Hip circumference was measured around the widest portion of the buttocks. Ageand sex-specific body mass index (BMI) $z$ scores were calculated using the 2007 World Health Organization (WHO) method, ${ }^{30}$ and children were classified as overweight or obese if the BMI $z$ score was greater than one SD above the age- and sex-specific mean. This is equivalent to a BMI of $25 \mathrm{~kg} / \mathrm{m}^{2}$ at age 19 years. ${ }^{30}$

\section{Pulse Wave Analysis}

Peripheral systolic BP (SBP), peripheral diastolic BP (DBP), $\mathrm{SBP}$, and Alx were recorded using a $\mathrm{BP}+$ device (Uscom). The $\mathrm{BP}+$ device incorporates an oscillometric $\mathrm{BP}$ module, which complies with the Association for the Advancement of Medical Instrumentation (AAMI SP10) requirements and receives an $A / A$ rating from the British Hypertension Society evaluation protocol. ${ }^{31}$ Following 20 minutes of undisturbed supine rest, oscillometric pressure waveforms were recorded in patients by a single operator on the left upper arm, following standard manufacturer guidelines. ${ }^{32}$ Each measurement cycle was $\approx 40$ seconds, consisting of a brachial BP recording and then a 10-second suprasystolic recording. A corresponding aortic pressure waveform was generated using a validated transfer function, from which cSBP was estimated. ${ }^{33}$ Alx was calculated from the suprasystolic waveform using the formula: $A l x=\left(P_{3}-P_{0}\right) /\left(P_{1}-P_{0}\right)$, where $P_{0}$ denotes the pressure at the onset of the pulse, $P_{1}$ the peak pressure of the incident wave, and $\mathrm{P}_{3}$ the peak pressure of the reflective wave. However, for $\mathrm{HbA} 1 \mathrm{c}$ and glucose, along with triglycerides, $<40 \%$ of their variance is explained by a 4 -factor model.

\section{Cardiac and Metabolic Markers}

Standard finger prick procedures were used to extract capillary blood for measurement of fasting total cholesterol, high-density lipoprotein cholesterol, low-density lipoprotein cholesterol, triglycerides, serum glucose (CardioChek PA, PTS Diagnostics), ${ }^{35}$ and $\mathrm{HbA}_{1 \mathrm{c}}$ (A1CNow+, PTS Diagnostics). ${ }^{36}$

\section{Statistical Analysis}

Statistical analyses were performed using SPSS version 22 (SPSS, Inc) and HLM6 (Scientific Software International, Inc).
The corresponding author (L.S.) had full access to the data in the study and was responsible for the integrity of the data set and the data analysis. Only children with full data sets were included in the analyses.

Participant data are summarized by counts and proportions and mean and SD for all participants and by sex.

Table 1. Participant Data Description

\begin{tabular}{|c|c|c|c|}
\hline \multirow[b]{2}{*}{ Categorical Variables } & All $(\mathrm{N}=392)$ & Girls $(n=197)$ & Boys $(n=195)$ \\
\hline & No. (\%) & No. (\%) & No. (\%) \\
\hline \multicolumn{4}{|l|}{ Ethnicity } \\
\hline New Zealand European & $279(71)$ & $135(69)$ & $144(74)$ \\
\hline Māori & $37(9)$ & $21(11)$ & $16(8)$ \\
\hline Pacific & $22(6)$ & $12(6)$ & $10(5)$ \\
\hline Not recorded & $54(14)$ & $29(15)$ & $25(13)$ \\
\hline \multicolumn{4}{|l|}{ School year } \\
\hline 4 & $82(21)$ & $45(23)$ & $37(19)$ \\
\hline 5 & $114(29)$ & $55(28)$ & $59(30)$ \\
\hline 6 & $127(32)$ & $62(31)$ & $65(33)$ \\
\hline 7 & $69(18)$ & $35(18)$ & $34(17)$ \\
\hline \multicolumn{4}{|l|}{ School decile } \\
\hline $\operatorname{Low}(\leq 5)$ & $211(54)$ & $106(54)$ & $105(54)$ \\
\hline High $(>5)$ & $181(46)$ & $91(46)$ & $90(46)$ \\
\hline \multicolumn{4}{|l|}{ Obesity status } \\
\hline Overweight & $113(29)$ & $60(30)$ & $53(27)$ \\
\hline Nonoverweight & $279(71)$ & $137(70)$ & $142(73)$ \\
\hline \multirow[b]{2}{*}{ Continuous Variables } & \multicolumn{3}{|l|}{ Mean (SD) } \\
\hline & $\begin{array}{l}\text { All (N=392) } \\
\text { No. }(\%)\end{array}$ & $\begin{array}{l}\text { Girls }(n=197) \\
\text { No. }(\%)\end{array}$ & $\begin{array}{l}\text { Boys }(n=195) \\
\text { No. }(\%)\end{array}$ \\
\hline BMI, $\mathrm{kg} / \mathrm{m}^{2}$ & $17.9(3.25)$ & $17.9(3.1)$ & $17.8(3.4)$ \\
\hline Age, y & $9.54(1.1)$ & $9.52(1.16)$ & $9.56(1.04)$ \\
\hline Waist circumference, $\mathrm{cm}$ & $20.3(9.39)$ & $18.6(9.1)$ & $22(9.37)$ \\
\hline $\mathrm{SBP}, \mathrm{mm} \mathrm{Hg}$ & $101(7.91)$ & $101(8.21)$ & $101(7.61)$ \\
\hline $\mathrm{DBP}, \mathrm{mm} \mathrm{Hg}$ & $61.7(6.32)$ & $62(6.52)$ & $61.4(6.11)$ \\
\hline cSBP, mm Hg & $93.2(9.04)$ & $93.2(10.6)$ & $93.3(7.13)$ \\
\hline Heart rate, beats/min & $74.8(11.4)$ & $77.5(12.1)$ & $72(9.87)$ \\
\hline $\mathrm{FBG}, \mathrm{mmol} / \mathrm{L}$ & $5.04(0.38)$ & $4.97(0.37)$ & $5.11(0.38)$ \\
\hline $\mathrm{HbA}_{1 \mathrm{c}}, \%$ & $5.11(0.31)$ & $5.12(0.32)$ & $5.1(0.31)$ \\
\hline $\mathrm{TC}, \mathrm{mmol} / \mathrm{L}$ & $3.55(0.6)$ & $3.61(0.56)$ & $3.49(0.62)$ \\
\hline $\mathrm{HDL}-\mathrm{C}, \mathrm{mmol} / \mathrm{L}$ & $1.47(0.39)$ & $1.42(0.33)$ & $1.52(0.43)$ \\
\hline LDL-C, mmol/L & $1.85(0.5)$ & $1.91(0.52)$ & $1.79(0.48)$ \\
\hline $\mathrm{TG}, \mathrm{mmol} / \mathrm{L}$ & $0.88(0.42)$ & $0.91(0.39)$ & $0.84(0.45)$ \\
\hline Alx, \% & $56(15.9)$ & $56.5(16.7)$ & $55.5(15.2)$ \\
\hline
\end{tabular}

Alx indicates augmentation index; BMI, body mass index; cSBP, central systolic blood pressure; DBP, diastolic blood pressure; FBG, fasting blood glucose; $\mathrm{HbA}_{1 \mathrm{c}}$, glycated hemoglobin; HDL-C, high-density lipoprotein cholesterol; LDL-C, low-density lipoprotein cholesterol; SBP, systolic blood pressure; TC, total cholesterol; TG, triglycerides. 
Table 2. Correlation Matrix of All Variables

\begin{tabular}{|c|c|c|c|c|c|c|c|c|c|c|c|c|c|}
\hline & BMI & Waist & SBP & DBP & HR & FBG & $\mathrm{HbA}_{1 \mathrm{c}}$ & TC & HDL-C & LDL-C & TG & cSBP & Alx \\
\hline BMI & 1.000 & 0.773 & 0.262 & 0.146 & 0.024 & 0.124 & 0.101 & -0.098 & -0.218 & -0.072 & 0.238 & 0.168 & -0.201 \\
\hline Waist & $\ldots$ & 1.000 & 0.307 & 0.240 & -0.011 & 0.125 & 0.151 & -0.071 & -0.208 & -0.019 & 0.222 & 0.205 & -0.201 \\
\hline DBP & $\ldots$ & $\ldots$ & $\ldots$ & 1.000 & 0.243 & 0.048 & -0.144 & -0.016 & 0.015 & 0.018 & 0.072 & 0.660 & 0.116 \\
\hline $\mathrm{HR}$ & $\ldots$ & $\ldots$ & $\ldots$ & $\cdots$ & 1.000 & 0.116 & -0.075 & 0.070 & -0.017 & 0.017 & 0.010 & 0.127 & -0.210 \\
\hline $\mathrm{HbA}_{1 \mathrm{c}}$ & $\ldots$ & $\ldots$ & $\ldots$ & $\ldots$ & $\ldots$ & $\ldots$ & 1.000 & 0.085 & -0.079 & 0.001 & 0.119 & -0.095 & 0.056 \\
\hline TC & $\ldots$ & $\ldots$ & $\ldots$ & $\ldots$ & $\ldots$ & $\ldots$ & 0.085 & 1.000 & 0.467 & 0.501 & 0.035 & 0.005 & -0.021 \\
\hline HDL-C & $\ldots$ & $\ldots$ & $\ldots$ & $\ldots$ & $\ldots$ & $\ldots$ & $\ldots$ & $\ldots$ & 1.000 & 0.017 & -0.193 & -0.032 & 0.023 \\
\hline TG & $\ldots$ & $\ldots$ & $\ldots$ & $\ldots$ & $\ldots$ & $\ldots$ & $\ldots$ & $\ldots$ & $\ldots$ & 1.000 & -0.159 & 0.002 & 0.017 \\
\hline
\end{tabular}

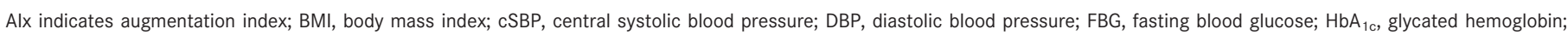
HDL-C, high-density lipoprotein cholesterol; HR, heart rate; LDL-C, low-density lipoprotein cholesterol; SBP, systolic blood pressure; TC, total cholesterol; TG, triglycerides.

Cardiometabolic factors were derived from a principal components analysis of the variables: SBP, DBP, cSBP, waist circumference, $\mathrm{BMI}$, triglyceride concentration, $\mathrm{HbA}_{1 \mathrm{c}}$, total cholesterol, low-density lipoprotein cholesterol, high-density lipoprotein cholesterol, Alx, and heart rate. The number of factors was determined by the minimum eigenvalue principle of a principal components analysis of the correlation matrix. The number of factors was determined by the number of eigenvalues $>1$, the implication being that if an eigenvalue is $<1$, the derived dimension captures less variability in the

Table 3. Cardiometabolic Factor Correlations and Communalities

\begin{tabular}{|l|l|l|l|l|l|}
\hline & Factor 1 & Factor 2 & Factor 3 & \multirow{2}{*}{ Factor 4 } & \multirow{2}{*}{ Communality } \\
\cline { 2 - 5 } & Blood Pressure & Adiposity & Lipids & Vascular & 0.85 \\
\hline SBP & $0.89^{\star}$ & 0.14 & 0.07 & 0.16 & 0.07 \\
\hline DBP & $0.89^{\star}$ & 0.04 & 0.00 & 0.04 & 0.80 \\
\hline CSBP & $0.87^{\star}$ & 0.10 & -0.01 & -0.09 & 0.77 \\
\hline Waist circumference & 0.21 & $0.82^{*}$ & -0.05 & 0.25 & 0.79 \\
\hline BMI & 0.15 & $0.81^{*}$ & -0.10 & 0.29 & 0.76 \\
\hline TG & 0.08 & $0.51^{*}$ & -0.11 & -0.22 & 0.32 \\
\hline HbA $A_{1 C}$ & -0.23 & $0.47^{*}$ & 0.14 & -0.28 & 0.37 \\
\hline TC & 0.01 & 0.02 & $0.92^{*}$ & -0.05 & 0.84 \\
\hline LDL-C & 0.01 & 0.03 & $0.71^{*}$ & 0.01 & 0.50 \\
\hline HDL-C & 0.04 & -0.34 & $0.55^{*}$ & -0.02 & 0.42 \\
\hline Alx & 0.20 & -0.16 & -0.07 & $-0.74^{*}$ & 0.61 \\
\hline HR & 0.28 & -0.16 & 0.07 & $0.57^{*}$ & 0.43 \\
\hline FBG & 0.03 & 0.04 & -0.11 & $0.50^{*}$ & 0.27 \\
\hline Eigenvalue & 2.6 & 2.0 & 1.7 & 1.4 & \\
\hline Percentage of variance explained & 20 & 15 & 13 & 11 & \\
\hline Percentage of cumulative variance & 20 & 35 & 49 & 60 & \\
\hline
\end{tabular}

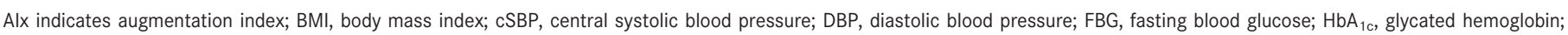
HDL-C, high-density lipoprotein cholesterol; HR, heart rate; LDL-C, low-density lipoprotein cholesterol; SBP, systolic blood pressure; TC, total cholesterol; TG, triglycerides.

*variable loads on to factor based on loading of $>0.40$. 


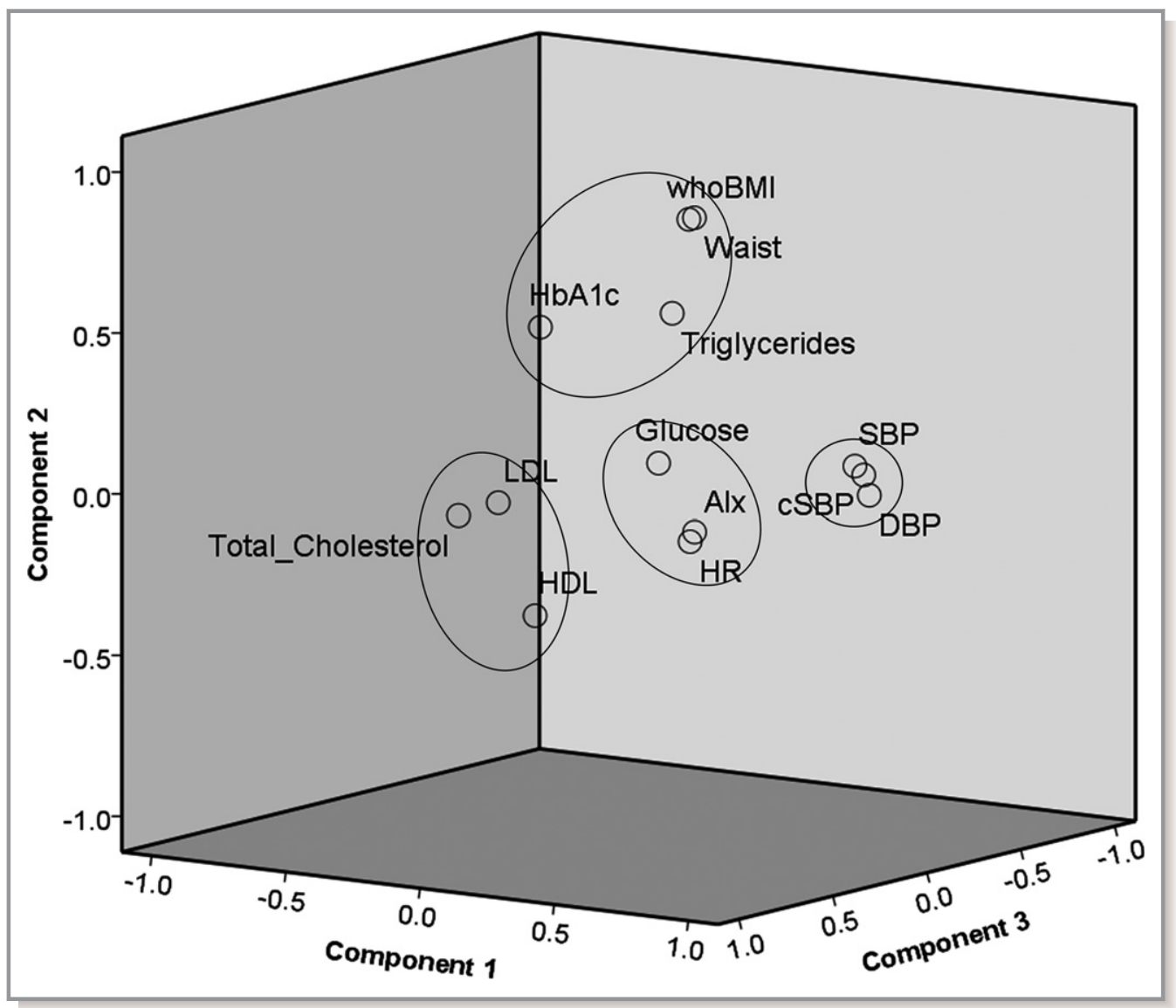

Figure. Component plots with factor diagrams from principle component analysis with varimax rotation. Alx indicates augmentation index; cSBP, central systolic blood pressure; DBP, diastolic blood pressure; $\mathrm{HbA} 1 \mathrm{c}$, glycated hemoglobin; HDL, high-density lipoprotein; HR, heart rate; LDL, low-density lipoprotein; SBP, systolic blood pressure; whoBMI, body mass index $z$ scores, calculated using the 2007 World Health Organization method.

data than any single variable. The principal components were then subject to orthogonal "varimax" rotation and the factor loadings, the correlation between the derived factors and the underlying variables, were used to interpret each factor. We used a loading of $>0.40$ to interpret the factor pattern. In the event (and as described in the Results section) we identified 4 factors representing BP, adiposity, lipids, and vascular. From this factor structure we then derived a cardiometabolic risk factor by summing the individual factor scores for each individual and the 4 factors as a summary risk score.

To determine whether overweight-obese status was associated with heightened risk for poor cardiometabolic health, the individual factor scores and the summary risk score were then used as response variables in separate hierarchical linear models. Overweight-obesity status was specified as a dummycoded variable (normal-weight $=0$, overweight-obese $=1$ ) using the 2007 WHO criteria $^{30}$ as discussed above. In these models, we also adjusted for age, sex, ethnicity, and socioeconomic status (as indicated by the decile of the school the participants attended). Although the derived individual factors and the summed risk score represent cardiometabolic indicators, there is no natural interpretation of the differences in these factor scores in relation to the body weight indicator variable. Therefore, standardized effect sizes were estimated by dividing the pooled variance by the mean difference between groups, ie, the $\beta$ for overweight-obesity. We used cut points suggested by Cohen ${ }^{37}$ of: $0.20,0.50$, and 0.80 to represent small, medium, and large associations, respectively.

\section{Results}

Study participants are described in Table 1. All children had complete data sets and were included in the analyses.

Correlations among all variables are shown in Table 2, and the factor analysis is summarized in Table 3 and the Figure. Using the minimum eigenvalue principle, of $>1$, four dimensions were retained in the factor analysis. The table 
Table 4. Hierarchical Linear Model Associations Between Overweight-Obesity Status and Individual and Cumulative Cardiometabolic Risk Derived From Factor Analysis

\begin{tabular}{|c|c|c|c|c|c|c|c|c|}
\hline & \multicolumn{4}{|c|}{ Unadjusted } & \multicolumn{4}{|l|}{ Adjusted } \\
\hline \multicolumn{9}{|l|}{ Adiposity } \\
\hline Overweight-obese & 1.459 & 0.083 & $<0.001$ & 1.368 & 1.423 & 0.085 & $<0.001$ & 1.282 \\
\hline \multicolumn{9}{|l|}{ Blood pressure } \\
\hline Overweight-obese & 0.173 & 0.108 & 0.108 & 0.105 & 0.159 & 0.110 & 0.150 & 0.093 \\
\hline \multicolumn{9}{|l|}{ Lipids } \\
\hline Intercept & 0.014 & 0.112 & 0.906 & & -0.006 & 0.111 & 0.956 & \\
\hline Overweight-obese & -0.061 & 0.111 & 0.582 & -0.040 & -0.035 & 0.114 & 0.759 & -0.023 \\
\hline \multicolumn{9}{|l|}{ Cumulative } \\
\hline Intercept & -0.569 & 0.184 & 0.013 & & -0.566 & 0.198 & 0.019 & \\
\hline Overweight-obese & 2.008 & 0.194 & $<0.001$ & 0.782 & 1.996 & 0.198 & $<0.001$ & 0.738 \\
\hline
\end{tabular}

Adjusted model: age, sex, ethnicity, and socioeconomic status. Effect sizes were estimated by dividing the pooled variance by the mean difference between groups. ES indicates standardized effect size.

shows the correlation of each variable with the 4 factors and these factors are labelled: a BP factor, adiposity factor, lipid factor, and vascular factor. Collectively, the 4 factors explained $60 \%$ of the variance in the measured variables. The cSBP loaded positively onto the BP factor, but no other factor. The $\mathrm{HbA}_{1 \mathrm{c}}$ loaded positively onto the adiposity factor, whereas FBG loaded positively onto the vascular factor. However, for $\mathrm{HbA} 1 \mathrm{c}$ and glucose, along with triglycerides, $<40 \%$ of their variance is explained by a 4-factor model.

The associations between weight status, overweight-obese $(n=113)$ compared with not $(n=279)$, with the individual factor scores and the cumulative risk score are shown in Table 4. Standardized effect sizes are also reported to illustrate the strength of association, as discussed in the Methods section. There is a medium and statistically significant association between the cumulative risk score and overweight-obesity status. Inspection of the individual factors reveals that, as might be anticipated, the strongest association was between the adiposity factor and overweight-obesity status. However, there was also a small but statistically significant association between the overweight-obesity status and the vascular factor. There was no important association with the lipid or BP factors.

Table 5 presents example linear combinations for each factor, using one overweight and one normal-weight girl, both of which are aged 10 years.

\section{Discussion}

The results of the analysis of cardiometabolic risk in this study suggest that one common factor does not fully explain cardiometabolic health in preadolescent children. Four factors were identified, BP, adiposity, cholesterol, and vascular factors, of which the majority of the variance was explained by BP. Each of these factors, except vascular, which was predominantly explained by Alx, were consistent with similar studies conducted in children. ${ }^{1-14}$ An additional novel finding was that $\mathrm{HbA}_{1 \mathrm{c}}$ and $\mathrm{FBG}$ loaded onto different factors, supporting previous work suggesting that FBG indicates shortterm glycemic control, ${ }^{16}$ whereas $\mathrm{HbA}_{1 \mathrm{c}}$ reflects chronic glycemic control. ${ }^{17}$ Lastly, we found that overweight-obese children were more likely to have higher (worse) risk scores for adiposity, vascular, and cumulative risk scores.

\section{Study Strengths and Limitations}

While our findings are internally robust, this study had several potential limitations. First, the majority of the participants were New Zealand European (white), and whether this factor structure would generalize to other population subgroups is unclear. Nonetheless, the proportion of Maori (9\% versus national: 14\%) and Pacific (6\% versus national: 7\%) participants are close to nationally representative. ${ }^{38}$ Further, past reports from factor analysis studies with child participants have not identified important differences in factor patterns 
Table 5. Example Linear Combinations for Each Factor Using One Overweight-Obese and One Normal-Weight Girl, Aged 10 y

\begin{tabular}{|c|c|c|c|c|c|c|c|c|c|c|}
\hline & \multicolumn{5}{|c|}{ Overweight (BMI: +2 SD) } & \multicolumn{5}{|c|}{ Normal-Weight (BMI: -2 SD) } \\
\hline SBP & -0.99 & -0.89 & -0.14 & -0.07 & -0.16 & 0.46 & 0.41 & 0.06 & 0.03 & 0.07 \\
\hline cSBP & -0.85 & -0.74 & -0.08 & 0.01 & 0.08 & 0.59 & 0.51 & 0.06 & -0.01 & -0.05 \\
\hline Waist circumference & 0.90 & 0.19 & 0.74 & -0.04 & 0.23 & -1.20 & -0.25 & -0.99 & 0.06 & -0.30 \\
\hline $\mathrm{TG}$ & 0.10 & 0.01 & 0.05 & -0.01 & -0.02 & -0.42 & -0.04 & -0.21 & 0.05 & 0.09 \\
\hline $\mathrm{HbA}_{1 \mathrm{c}}$ & 0.29 & -0.07 & 0.14 & 0.04 & -0.08 & -0.35 & 0.08 & -0.16 & -0.05 & 0.10 \\
\hline $\mathrm{TC}$ & -0.56 & 0.00 & -0.01 & -0.51 & 0.03 & -0.28 & 0.00 & 0.00 & -0.25 & 0.01 \\
\hline LDL-C & -0.48 & 0.00 & -0.01 & -0.34 & -0.01 & -0.30 & 0.00 & -0.01 & -0.21 & 0.00 \\
\hline $\mathrm{FBG}$ & -0.37 & -0.01 & -0.01 & 0.04 & -0.19 & -1.15 & -0.04 & -0.04 & 0.13 & -0.58 \\
\hline \multicolumn{11}{|c|}{ Linear combinations by factor } \\
\hline $\mathrm{BP}$ & & -2.66 & & & & & 1.07 & & & \\
\hline Adiposity & & & 2.08 & & & & & -2.97 & & \\
\hline Lipids & & & & -1.35 & & & & & -0.27 & \\
\hline Vascular & & & & & 0.99 & & & & & -2.05 \\
\hline
\end{tabular}

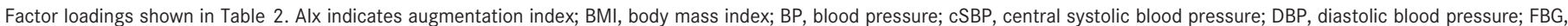

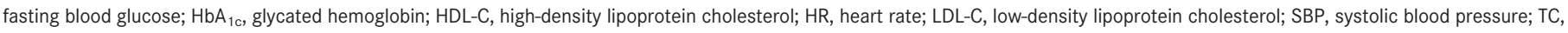
total cholesterol; TG, triglycerides.

based on demographic characteristics. ${ }^{13,14}$ Second, our sample was recruited from 3 major cities and did not recruit from rural areas, which may limit the generalizability of our findings. However, the 3 cities were geographically varied and wide sample zones were utilized within these regions. Third, body composition was evaluated using typical epidemiological measures, including BMI and waist circumference. Subsequent investigation is warranted utilizing assessments that can distinguish fat and fat-free mass, such as dual-energy $x$-ray absorptiometry or bioimpedance analysis. Finally, this was a cross-sectional study, and further longitudinal studies are needed to determine whether the identified factors present different pathological processes.

\section{Comparison With Other Studies}

Our findings are consistent with similar studies conducted in children, ${ }^{11-14}$ each of which identified a BP factor: 3 of which identified a lipids/cholesterol factor ${ }^{11,12,14}$ and 2 of which identified adiposity. ${ }^{11,12}$ For the 2 studies that did not identify adiposity as a factor, only one adiposity variable (BMI) was specified, which loaded onto 2 factors in one study ${ }^{11}$ and one factor only in the other study. ${ }^{13}$ For the current analysis, 2 body composition variables were utilized (BMI and waist circumference) and only loaded onto one factor, using a cut point of 0.4. An additional important difference between the current analysis and past studies is that cSBP, Alx, and $\mathrm{HbA}_{1 \mathrm{c}}$ were included in the analysis. While cSBP loaded onto the BP factor, the interpretation is not different from previous studies. However, Alx and $\mathrm{HbA}_{1 \mathrm{c}}$ loadings do affect the interpretation of findings.

The Alx represents central arterial wave reflection, which depends primarily on aortic stiffness. ${ }^{39}$ In young healthy patients, the reflected wave arrives back at the ascending aorta during diastole, enhancing diastolic coronary perfusion. However, as the arterial system stiffens, the pulse waves travel faster and get reflected sooner, thereby arriving back at the ascending aorta during systole and augmenting CSBP and increasing afterload. The findings from this study indicate that the Alx and BP, including cSBP, represent different constructs, and that Alx may be an important cardiovascular measurement in children. In adults, a meta-analysis ${ }^{24}$ of 11 longitudinal studies ( $n=5648$, mean follow-up 45 months) reports that a $10 \%$ increase in Alx increases the risk of future cardiovascular events and all-cause mortality by $32 \%$ and $38 \%$, respectively. In children, a limited number of studies have 
employed this methodology, ${ }^{40-44}$ and findings from this study support the need to generate reference values relevant to children.

The finding that $\mathrm{HbA}_{1 \mathrm{c}}$ loaded onto the adiposity factor, while FBG loaded onto the vascular factor, is consistent with research identifying that the these two variables reflect different underlying physiological constructs, with FBG reflecting short-term glycemic control ${ }^{16}$ and $\mathrm{HbA}_{1 \mathrm{c}}$ reflecting chronic glycemic control. ${ }^{17}$ The American Heart Association has recommended an ideal FBG of $<5.55 \mathrm{mmol} / \mathrm{L}$ (100 mg/ $\mathrm{dL})$ for pediatric patients, ${ }^{45}$ which was exceeded by $16 \%$ $(n=61)$ of the children in the current sample. However, there is evidence to suggest that hyperinsulinism is the first metabolic abnormality seen in obese pediatric patients, and impaired fasting glucose occurs at a much later stage in the progression toward type 2 diabetes mellitus. ${ }^{46,47}$ Further, in adults, $\mathrm{HbA}_{1 \mathrm{c}}$ and $\mathrm{FBG}$ are also differentially associated with cardiovascular risk profiles, ${ }^{18}$ with $\mathrm{HbA}_{1 \mathrm{c}}$ being more strongly associated with increased risk of cardiovascular events than FBG. ${ }^{19,20}$ While the findings from the current study cannot corroborate the previous findings in adults, both the adiposity $\left(\mathrm{HbA}_{1 \mathrm{c}}\right)$ and vascular (FBG) factors were significantly worse for overweight-obese children compared with normal-weight children.

In the current sample, $29 \%(n=113)$ of children were overweight-obese. This is consistent with New Zealand national estimates of prevalence of $33 \%$. The overweightobese children were more likely to have higher (worse) risk scores for the adiposity (large effect), vascular (small effect), and cumulative risk scores (medium effect). These differences are striking because these children are preadolescent and otherwise healthy. This suggests that adiposity and vascular targets may be important for screening overweight-obese children and refining their risk of future cardiovascular events.

\section{Implications}

This analysis indicates that the clustering of cardiometabolic risks variables can be used to derive summary factors and a cumulative risk score in pediatric populations. These factors and the cumulative risk score may enable the early identification of at-risk populations and may help in the design of longitudinal studies of trajectories of cardiometabolic risk.

\section{Conclusions}

The purpose of this study was to explore: (1) underlying factors that explain cardiometabolic risk factors in preadolescents using principle components analysis; (2) the unique value of $\mathrm{HbA}_{1 \mathrm{c}}, \mathrm{cSBP}$, and Alx in these factors; and (3) the associations between being overweight or obese in preadolescent children in relation to these underlying factors. Four factors were identified, including BP, adiposity, cholesterol, and vascular factors. Each of the factors, except vascular, which was predominantly explained by Alx, is consistent with similar studies conducted in children. An additional novel finding was that $\mathrm{HbA}_{1 \mathrm{c}}$ and $\mathrm{FBG}$ loaded onto different factors, supporting previous work suggesting that FBG indicates shortterm glycemic control, whereas $\mathrm{HbA}_{1 \mathrm{c}}$ reflects chronic glycemic control. Lastly, we found that overweight-obese children were more likely to have higher (worse) risk scores for the adiposity, vascular, and cumulative risk factors. These findings suggest that the identified factors and cumulative risk score may enable the early identification of at-risk populations and help in the design of longitudinal studies of trajectories of cardiometabolic risk.

\section{Disclosures}

None.

\section{References}

1. Berenson GS, Srinivasan SR, Bao W, Newman WP III, Tracy RE, Wattigney WA. Association between multiple cardiovascular risk factors and atherosclerosis in children and young adults. The Bogalusa Heart Study. N Engl J Med. 1998;338:1650-1656

2. Chen W, Bao W, Begum S, Elkasabany A, Srinivasan SR, Berenson GS. Agerelated patterns of the clustering of cardiovascular risk variables of syndrome $X$ from childhood to young adulthood in a population made up of black and white subjects: the Bogalusa Heart Study. Diabetes. 2000;49:1042-1048.

3. Olshansky SJ, Passaro DJ, Hershow RC, Layden J, Carnes BA, Brody J, Hayflick L, Butler RN, Allison DB, Ludwig DS. A potential decline in life expectancy in the United States in the 21st century. N Engl J Med. 2005;352:1138-1145.

4. Hill JO, Wyatt HR, Reed GW, Peters JC. Obesity and the environment: where do we go from here? Science. 2003;299:853-855.

5. Stoner L, Stoner KR, Young JM, Fryer S. Preventing a cardiovascular disease epidemic among indigenous populations through lifestyle changes. Int J Prev Med. 2012;3:230-240.

6. Reaven GM. Banting lecture 1988. Role of insulin resistance in human disease. Diabetes. 1988;37:1595-1607.

7. Goodman E, Dolan LM, Morrison JA, Daniels SR. Factor analysis of clustered cardiovascular risks in adolescence: obesity is the predominant correlate of risk among youth. Circulation. 2005;111:1970-1977.

8. Gurka MJ, Ice CL, Sun SS, Deboer MD. A confirmatory factor analysis of the metabolic syndrome in adolescents: an examination of sex and racial/ethnic differences. Cardiovasc Diabetol. 2012;11:128.

9. Li C, Ford ES. Is there a single underlying factor for the metabolic syndrome in adolescents? A confirmatory factor analysis Diabetes Care. 2007;30:1556-1561.

10. Khader YS, Batieha A, Jaddou H, Batieha Z, El-Khateeb M, Ajlouni K. Factor analysis of cardiometabolic risk factors clustering in children and adolescents. Metab Syndr Relat Disord. 2011;9:151-156.

11. Viitasalo A, Lakka TA, Laaksonen DE, Savonen K, Lakka HM, Hassinen M, Komulainen P, Tompuri T, Kurl S, Laukkanen JA, Rauramaa R. Validation of metabolic syndrome score by confirmatory factor analysis in children and adults and prediction of cardiometabolic outcomes in adults. Diabetologia. 2014;57:940-949.

12. Goodman E, Li C, Tu YK, Ford E, Sun SS, Huang TT. Stability of the factor structure of the metabolic syndrome across pubertal development: confirmatory factor analyses of three alternative models. J Pediatr. 2009;155:S5.e1-8.

13. Chen W, Srinivasan SR, Elkasabany A, Berenson GS. Cardiovascular risk factors clustering features of insulin resistance syndrome (Syndrome X) in a biracial (Black-White) population of children, adolescents, and young adults: the Bogalusa Heart Study. Am J Epidemiol. 1999;150:667-674. 
14. Lambert M, Paradis G, O'Loughlin J, Delvin EE, Hanley JA, Levy E. Insulin resistance syndrome in a representative sample of children and adolescents from Quebec, Canada. Int J Obes Relat Metab Disord. 2004;28:833-841.

15. International Diabetes Federation (IDF). IDF definition of metabolic syndrome in children and adolescents. 2016. Available at: http://www.idf.org/metab olic-syndrome/children. Accessed August 3, 2016.

16. Rodbard D. Interpretation of continuous glucose monitoring data: glycemic variability and quality of glycemic control. Diabetes Technol Ther. 2009;11 (suppl 1):S55-S67.

17. Waden J, Forsblom C, Thorn LM, Gordin D, Saraheimo M, Groop PH; Finnish Diabetic Nephropathy Study G. A1C variability predicts incident cardiovascular events, microalbuminuria, and overt diabetic nephropathy in patients with type 1 diabetes. Diabetes. 2009;58:2649-2655.

18. Qie LY, Sun JP, Ning F, Pang ZC, Gao WG, Ren J, Nan HR, Zhang L, Qiao Q; Qingdao Diabetes Survey Group in A. Cardiovascular risk profiles in relation to newly diagnosed type 2 diabetes diagnosed by either glucose or $\mathrm{HbA} 1 \mathrm{c}$ criteria in Chinese adults in Qingdao, China. Diabet Med. 2014;31:920-926.

19. Kim HK, Lee JB, Kim SH, Jo MW, Kim EH, Hwang JY, Bae SJ, Jung CH, Lee WJ, Park JY, Park GM, Kim YH, Choe J. Association of prediabetes defined by fasting glucose, $\mathrm{HbA} 1 \mathrm{c}$ only, or combined criteria with the risk of cardiovascular disease in Koreans. J Diabetes. 2016;8:657-666.

20. Lind M, Tuomilehto J, Uusitupa M, Nerman O, Eriksson J, llanne-Parikka P, Keinanen-Kiukaanniemi S, Peltonen M, Pivodic A, Lindstrom J. The association between $\mathrm{HbA} 1 \mathrm{c}$, fasting glucose, 1-hour glucose and 2-hour glucose during an oral glucose tolerance test and cardiovascular disease in individuals with elevated risk for diabetes. PLoS One. 2014;9:e109506.

21. Protogerou AD, Papaioannou TG, Blacher J, Papamichael CM, Lekakis JP, Safar ME. Central blood pressures: do we need them in the management of cardiovascular disease? Is it a feasible therapeutic target? J Hypertens. 2007;25:265-272.

22. Agabiti-Rosei E, Mancia G, O'Rourke MF, Roman MJ, Safar ME, Smulyan H, Wang JG, Wilkinson IB, Williams B, Vlachopoulos C. Central blood pressure measurements and antihypertensive therapy: a consensus document. Hypertension. 2007;50:154-160.

23. Avolio AP, Van Bortel LM, Boutouyrie P, Cockcroft JR, McEniery CM, Protogerou AD, Roman MJ, Safar ME, Segers P, Smulyan H. Role of pulse pressure amplification in arterial hypertension: experts' opinion and review of the data. Hypertension. 2009;54:375-383.

24. Vlachopoulos C, Aznaouridis K, O'Rourke MF, Safar ME, Baou K, Stefanadis C. Prediction of cardiovascular events and all-cause mortality with central haemodynamics: a systematic review and meta-analysis. Eur Heart J. 2010;31:1865-1871.

25. Weber T, O'Rourke MF, Lassnig E, Porodko M, Ammer M, Rammer M, Eber B. Pulse waveform characteristics predict cardiovascular events and mortality in patients undergoing coronary angiography. J Hypertens. 2010;28:797-805.

26. Fraser CG. Biological Variation: From Principles to Practice. Washington, DC: AACC Press; 2001.

27. Young Y, Abdolhosseini P, Brown F, Faulkner J, Lambrick D, Williams MA, Stoner L. Reliability of oscillometric central blood pressure and wave reflection readings: effects of posture and fasting. J Hypertens. 2015;33:1588-1593.

28. von Elm E, Altman DG, Egger M, Pocock SJ, Gotzsche PC, Vandenbroucke JP; Initiative $S$. The strengthening the reporting of observational studies in epidemiology (STROBE) statement: guidelines for reporting observational studies. Lancet. 2007;370:1453-1457.

29. Castro N, Faulkner J, Skidmore P, Williams M, Lambrick DM, Signal L, Thunders M, Muller D, Lark S, Hamlin M, Lane AM, Kingi TK, Stoner L. Pre-adolescent cardio-metabolic associations and correlates: PACMAC methodology and study protocol. BMJ Open. 2014;4:e005815.

30. de Onis M, Onyango AW, Borghi E, Siyam A, Nishida C, Siekmann J. Development of a WHO growth reference for school-aged children and adolescents. Bull World Health Organ. 2007;85:660-667.
31. Lowe A, Harrison W, El-Aklouk E, Ruygrok P, Al-Jumaily AM. Non-invasive model-based estimation of aortic pulse pressure using suprasystolic brachial pressure waveforms. J Biomech. 2009;42:2111-2115.

32. Stoner L, Lambrick DM, Faulkner J, Young J. Guidelines for the use of pulse wave analysis in adults and children. J Atheroscler Thromb. 2013;20:404-406.

33. Butlin M, Qasem A, Avolio AP. Estimation of central aortic pressure waveform features derived from the brachial cuff volume displacement waveform. Conf Proc IEEE Eng Med Biol Soc. 2012;2012:2591-2594.

34. Stoner L, Lambrick DM, Westrupp N, Young J, Faulkner J. Validation of oscillometric pulse wave analysis measurements in children. Am J Hypertens. 2014;27:865-872.

35. Parikh P, Mochari H, Mosca L. Clinical utility of a fingerstick technology to identify individuals with abnormal blood lipids and high-sensitivity C-reactive protein levels. Am J Health Promot. 2009;23:279-282.

36. Barrett SC, Huffman FG, Johnson P. Validation of finger-prick testing of fasting blood glucose, total cholesterol, and $\mathrm{HbA1c}$ in adolescents. Point Care. 2011;10:51-58.

37. Cohen J. Statistical Power Analysis for the Behavioral Sciences. Hillsdale, NJ: L. Erlbaum Associates; 1988.

38. Statistics New Zealand. 2013 census quickstats about culture and identity. 2014; 2017. Available at: http://www.stats.govt.nz/Census/2013-census/ profile-and-summary-reports/quickstats-culture-identity.aspx. Accessed May 2, 2017.

39. Kelly RP, Millasseau SC, Ritter JM, Chowienczyk PJ. Vasoactive drugs influence aortic augmentation index independently of pulse-wave velocity in healthy men. Hypertension. 2001;37:1429-1433.

40. Lurbe E, Carvajal E, Torro I, Aguilar F, Alvarez J, Redon J. Influence of concurrent obesity and low birth weight on blood pressure phenotype in youth. Hypertension. 2009;53:912-917.

41. Covic A, Mardare N, Gusbeth-Tatomir P, Brumaru O, Gavrilovici C, Munteanu M, Prisada O, Goldsmith DJ. Increased arterial stiffness in children on haemodialysis. Nephrol Dial Transplant. 2006;21:729-735.

42. Heilman K, Zilmer M, Zilmer K, Lintrop M, Kampus P, Kals J, Tillmann V. Arterial stiffness, carotid artery intima-media thickness and plasma myeloperoxidase level in children with type 1 diabetes. Diabetes Res Clin Pract. 2009;84:168173.

43. Lurbe E, Torro I, Garcia-Vicent C, Alvarez J, Fernandez-Fornoso JA, Redon J. Blood pressure and obesity exert independent influences on pulse wave velocity in youth. Hypertension. 2012;60:550-555.

44. Lydakis C, Stefanaki E, Stefanaki S, Thalassinos E, Kavousanaki M, Lydaki D. Correlation of blood pressure, obesity, and adherence to the Mediterranean diet with indices of arterial stiffness in children. Eur J Pediatr. 2012;171:1373-1382.

45. Lloyd-Jones DM, Hong Y, Labarthe D, Mozaffarian D, Appel LJ, Van Horn L, Greenlund K, Daniels S, Nichol G, Tomaselli GF, Arnett DK, Fonarow GC, Ho PM, Lauer MS, Masoudi FA, Robertson RM, Roger V, Schwamm LH, Sorlie P, Yancy CW, Rosamond WD; American Heart Association Strategic Planning Task F, Statistics C. Defining and setting national goals for cardiovascular health promotion and disease reduction: the American Heart Association's strategic Impact Goal through 2020 and beyond. Circulation. 2010;121:586613.

46. Sharma S, Lustig RH, Fleming SE. Identifying metabolic syndrome in African American children using fasting HOMA-IR in place of glucose. Prev Chronic Dis. 2011;8:A64.

47. Steinberger J, Daniels SR, Hagberg N, Isasi CR, Kelly AS, Lloyd-Jones D, Pate RR, Pratt C, Shay CM, Towbin JA, Urbina E, Van Horn LV, Zachariah JP; American Heart Association Atherosclerosis $\mathrm{H}$, Obesity in the Young Committee of the Council on Cardiovascular Disease in the $\mathrm{Y}$, Council on $\mathrm{C}$, Stroke N, Council on E, Prevention, Council on Functional G, Translational B, Stroke C. Cardiovascular health promotion in children: challenges and opportunities for 2020 and beyond: a scientific statement from the American Heart Association. Circulation. 2016;134:e236-e255. 